\title{
| PASSO A PASSO DO GERENCIAMENTO DE PROJETOS
}

\section{Gisele S. B. CARVALHO}

Arquiteta com especialização em Gerenciamento de Projetos, Diretora da Myssior Gestão de Projetos

gisele@myssior.com.br

\section{RESUMO}

As empresas têm vivenciado nesta última década, um forte enxugamento dos quadros de pessoal e, em contra-partida, o aumento da necessidade de especialização técnica. Esta equação tem obrigado empresários a contratarem profissionais por período determinado, em muitos casos, por projetos específicos. Neste contexto, entender o processo de gerenciamento de projeto tem sido vital para as organizações, à medida que os novos negócios se constituem em regime de projetos, e passam a demandar uma série de técnicas gerenciais que nem sempre estão disponíveis nas empresas.

A abordagem de gerenciamento de projetos vem conquistando espaço e importância nos mais diversos setores, potencializando o melhor uso dos recursos para a obtenção de objetivos cada vez mais bem definidos pela organização.

De uma forma geral, já podemos verificar, hoje, um modelo onde os melhores quadros técnicos e o maior know-how não mais integram os quadros fixos dos empreendedores, mas encontram-se dispersos - e disponíveis - no mercado.

Palavras-chave: gerenciamento de projetos, compatibilização, projetos simultâneos.

\section{ABSTRACT}

Companies have experienced the reduction of their staff and the increase of the necessity for technical experience. This equation forced entrepreneurs to hire professionals for a specific period of time and in many cases for specifics purposes and specifics projects. In this context the understanding of the design management process has been vital to the organizations as long as new business are constituted of projects and they start to demand a several management techniques that aren't always available at the enterprises

The design management approaching has been taking space and becoming important at many different areas, increasing the better use of sources in order to obtain more defined goals for the organization.

In general, we can already verify that nowadays those who have the most important knowhow do not belong to the staff body in companies, they are found available and usually work as free lancers.

Keywords: design management, compatibility, simultaneous project 


\section{INTRODUÇÃO}

A crescente racionalização dos recursos humanos e programas de redução dos custos fixos nas empresas vêm produzindo um cenário antagônico.

Ao mesmo tempo em que a rentabilidade está, cada vez mais, na capacidade de planejar o projeto e precaver-se contra os riscos do negócio, os melhores quadros técnicos e know-how não mais integram os quadros fixos dos empreendedores, mas encontram-se dispersos - e disponíveis - no mercado.

Não por acaso, o gerenciamento de projetos tem adquirido relevâncias incontestes, reduzindo os riscos e o percurso para obtenção dos melhores resultados, com o maior controle, e melhores métodos, ampliando a capacidade das organizações de multiplicar-se em mais projetos simultâneos.

De acordo com o Guia PMBOK, "um projeto é um esforço temporário, com data de início e fim, empreendido para criar um produto, serviço ou resultado exclusivo."

Ainda de acordo com o PMBOK, “Gerenciamento de projetos é a aplicação de conhecimentos, habilidades, ferramentas e técnicas nas atividades do projeto a fim de atender os requisitos do projeto". Ou seja, dadas as metas e as restrições de recursos e tempo, cabe ao gerente de projetos garantir que ele atinja os objetivos propostos.

\section{FORMATOS DE GERENCIAMENTO}

Existem 03 formatos de Gerenciamento:

- Gerenciamento Forte: Quando a Gerenciadora é responsável por todas as disciplinas e é o agente pagador. Neste formato, ela tem equipe alocada em tempo integral no projeto. Tem autonomia para atuar em todas as áreas de conhecimento, principalmente: ESCOPO, CUSTOS e PRAZOS; o que maximiza seu potencial de sucesso.

- Gerenciamento Moderado: Quando o empreendedor contrata todas as disciplinas, mas a definição de Escopo, Prazo e Custo é feita pela gerenciadora. Neste formato, a Gerenciadora ainda preserva sua autoridade, pois tem conhecimento prévio do caminho crítico e como irá controlá-lo.

- Gerenciamento Fraco: Quando a equipe de projetistas é contratada pelo empreendedor, ou seja, escopo, custos e prazos já negociados previamente. Neste formato a Gerenciadora tem pouca ou nenhuma autoridade e os recursos humanos não são alocados por projeto. A Gerenciadora tem mais papel de coordenador do que gerenciamento.

Veja na tabela abaixo os pontos fortes e fracos de cada modelo. 


\begin{tabular}{|l|c|c|c|}
\hline $\begin{array}{r}\text { Modelo de } \\
\text { Gerenciamento } \\
\text { Co projerísticas }\end{array}$ & FORTE & MODERADO & FRACO \\
\hline Autonomia do gerente de projeto & $\begin{array}{c}\text { Pouca ou } \\
\text { nehuma }\end{array}$ & $\begin{array}{c}\text { Moderada ou } \\
\text { alta }\end{array}$ & $\begin{array}{c}\text { Alta a quase } \\
\text { total }\end{array}$ \\
\hline Disponibilidade de recursos & $\begin{array}{c}\text { Pouca ou } \\
\text { nehuma }\end{array}$ & $\begin{array}{c}\text { Moderada ou } \\
\text { alta }\end{array}$ & $\begin{array}{c}\text { Alta a quase } \\
\text { total }\end{array}$ \\
\hline $\begin{array}{l}\text { Disponibilidade de tempo do gerente } \\
\text { de projetos }\end{array}$ & Tempo Parcial & Tempo Integral & Tempo Integral \\
\hline Equipe alocada no projeto & Tempo Parcial & Tempo Integral & Tempo Integral \\
\hline
\end{tabular}

Tabela 1: Características de projeto e modelos de gerenciamento

O gerenciamento pode ser bem explicado através dos processos que o compõem, que podem ser reunidos em cinco grandes grupos e em nove áreas de conhecimento.

- Processo de Iniciação,

- Processo de Planejamento,

- Processo de Execução,

- Processo de Controle,

- Processo de Encerramento.

Embora os processos de gerenciamento de projetos sejam normalmente apresentados como componentes distintos com interfaces bem definidas, na prática, eles se sobrepõem e se integram constantemente, num processo cíclico.

Estes processos estão mais detalhados em: Metodologia Utilizada

As nove áreas de conhecimento, ou as competências necessárias ao gerente de projetos estão detalhadas abaixo, de forma seqüencial somente para facilitar ao leitor. No gerenciamento de um projeto estas competências estarão presentes em todo ciclo de vida do projeto e de forma simultânea.

1. Gerenciamento da Integração do Projeto: No contexto do gerenciamento de projetos, a integração inclui características de unificação, consolidação, negociação e articulação. Desta forma, faz-se necessário a escolha de uma metodologia de trabalho, com papeis bem definidos. Esta escolha deve ser feita a partir de alguns fatores: as exigências de cada mercado em que a empresa atua, a disponibilidade de mão-de-obra e a cultura organizacional necessária para adotá-la. Uma metodologia é um conjunto de regras de como conduzir um 
projeto com sucesso. O uso de uma metodologia, conhecido por todos os envolvidos dará maior controle sobre os recursos que serão adotados, responsáveis e etapas de aprovações. Controlando melhor o processo a equipe será mais eficiente, pois entregará o projeto com maior grau de acertos quanto as soluções técnicas, prazos e custos.

2. Gerenciamento do Escopo do Projeto: é o trabalho que deverá ser feito - com todas suas atividades - para se obter o produto com determinadas características. É essencial mapear o que fazer ao mesmo tempo em que é salutar identificar o que não deve ser feito. Tem um ditado que diz: “o ótimo é inimigo do bom", ou seja: enquanto perseguimos o "ótimo" nos distanciamos de algo que está bem mais próximo, o "bom", e que temos mais chance de obter sucesso. A arte de se definir o escopo do projeto passa por saber o que abandonar e o que reter do universo de necessidades do cliente. Definido o escopo, é necessário detalhar as atividades ou tarefas. O objetivo é chegar no nível de controle que será implementado ao projeto, ou seja: a WBS (Work Breakdown Structure).

3. Gerenciamento dos Prazos do Projeto: O cronograma do projeto foi iniciado no momento de detalhamento do escopo, todavia, necessitará de refinamento para se obter margens de erros reduzidas e admitidas. O caminho mais eficaz é chamar sua equipe de profissionais alocados no projeto para detalhar este cronograma conjuntamente, estimar a duração de cada uma das atividades e estabelecer o vínculo entre elas. A colaboração da pessoa que executará a atividade, na etapa de planejamento é saudável por duas razões: a primeira, porque ela é quem melhor sabe quanto tempo precisará e a segunda, que estará se comprometendo com os prazos assumidos.

Entretanto eles deverão partir de um cronograma macro, desenhado pelo gerente de projeto, a partir de experiências anteriores. Ao final, o gerente deverá validar a proposta de sua equipe. 


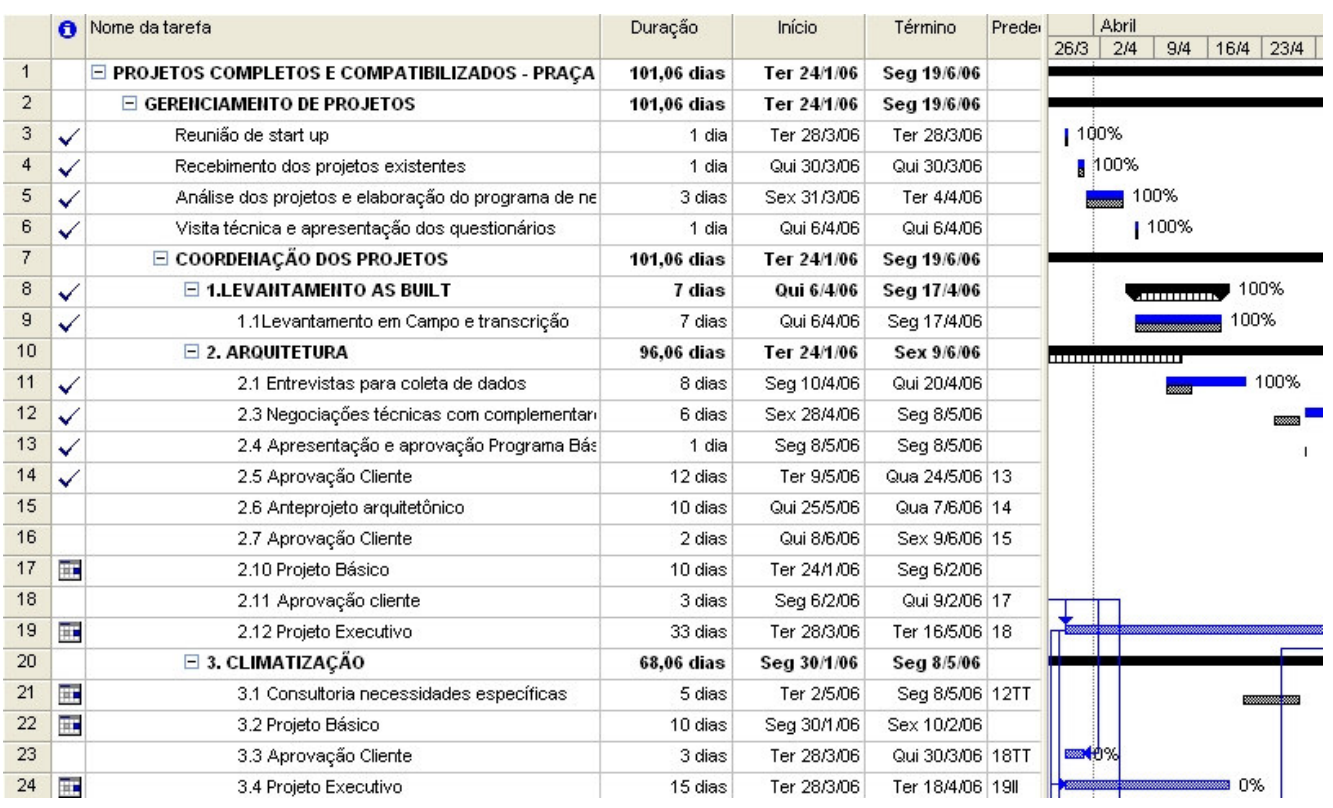

\section{Figura 1: Cronograma de projeto}

Veja na figura acima, que além de saber o que deve ser feito, é necessário conhecer a duração das atividades, inter-dependência e data de início e fim. Opcionalmente o nome do responsável. A duração é importante, mas se as atividades podem ser realizadas simultaneamente, como é ilustrado nesta figura a duração total do projeto, encurta. Esta análise de interdependência é essencial, caso contrário a visão simplista de que em projeto atrasado basta alocar mais recursos impera. Este procedimento raramente ajuda, uma vez que com mais gente, maior são as falhas de comunicação e o projeto que já estava atrasado, atrasa ainda mais.

Trazer mais gente é positivo quando há necessidade de suporte técnico, ou seja, a equipe está com dificuldade em dar resultados devido a falta de competência técnica, neste caso pode ser resolvido com a ajuda de um consultor.

Assim como elaborar o cronograma é essencial, controlá-lo talvez mais ainda. Quando a duração da atividade é grande, faz-se necessário estabelecer pontos de controle, que nada mais são, senão datas de medição do andamento do projeto, através de subprodutos ou relatórios de acompanhamento.

E atenção para não desatrelar evento físico de financeiro e correr o risco de pagar mais do que já recebeu.

4. Gerenciamento dos Custos do Projeto: Em paralelo deverá ser elaborado um orçamento, de acordo com número de horas de cada cargo necessário ao bom desenvolvimento dos trabalhos. Veja um modelo simples. 


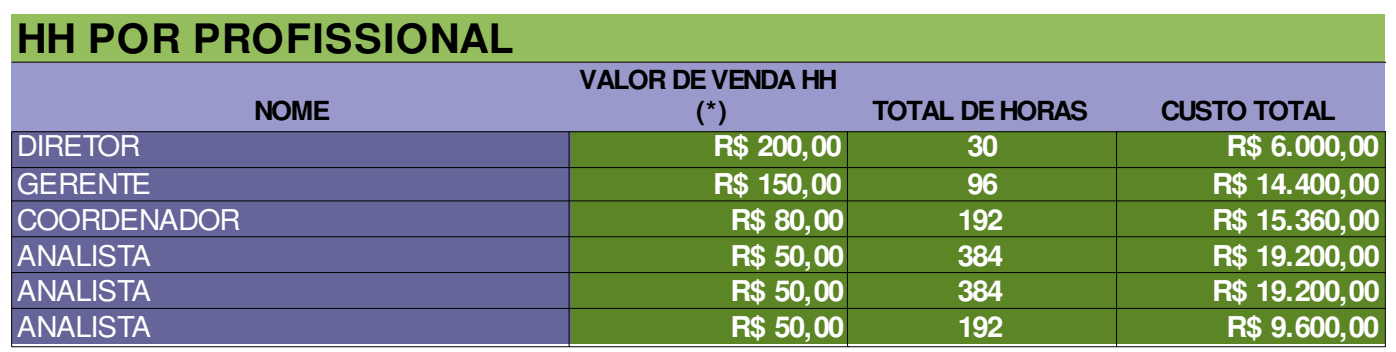

Tabela 2: Exemplo de Homens / Hora de profissionais de projetos

Para esta estimativa é necessário que o Gerente conheça o valor HH (homem/hora) de cada cargo e a quantidade de horas que serão necessárias para cada etapa. Para estimativas iniciais, estima-se uma margem de erro de $25 \%$. A medida que os profissionais são alocados ao projeto, o detalhamento das atividades será maior e o grau de assertividade do orçamento também. Vale lembrar que a experiência deste gerente em projetos anteriores fará muita diferença. Por exemplo, projetos com número elevado de sub-etapas que demandem aprovação do cliente necessitará de mais tempo, as vezes $50 \%$ a mais. A experiência do gerente do projeto conta muito nesta hora.

É essencial que o gerente do projeto saiba manter o escopo, dentro do que foi contratado inicialmente. Projetos cujo escopo vai sendo ampliado à medida que o cliente vai "descobrindo" suas reais necessidades e reformulando seus objetivos, têm sérias dificuldades em cumprir o cronograma e o orçamento.

Todavia, o gerente de projeto deverá ter cautela ao rejeitar um pedido do patrocinador do projeto, pois pode se indispor, mas se aceitar deverá avaliar com cuidado os prazos e orçamento que nem sempre têm "tanta gordura". Como eficiência é palavra de ordem nos dias atuais, os compromissos assumidos pelo gerente, não podem transformar em sacrifício, muitas vezes desnecessários, para toda a equipe. Desta forma, controlar e documentar o escopo se faz necessário.

5. Gerenciamento da Qualidade do Projeto: embora alguns persigam a idéia de surpreender o cliente, o gerente do projeto deve planejar e conduzir os trabalhos de forma a atender os requisitos do cliente. Qualidade é aquilo que é percebido pelo outro, embora nem sempre bem pago.

O time de projetistas deverá ter conhecimento detalhado do que se espera dos projetos, bem como, padrões e normas que serão aplicados. Projetos fora dos padrões de qualidade estabelecidos não deverão ser aceitos, caso contrário o gerente envia uma mensagem à equipe de projetos, que embora sejam exigidos determinados padrões, o nível de tolerância a erros é grande demais.

O melhor caminho para melhoria da qualidade, é o fornecedor perceber que você, como contratante, não ficou satisfeito. Ele pode melhorar em uma próxima ou ser eliminado da equipe, de acordo com os resultados obtidos. 
6. Gerenciamento dos Recursos Humanos do Projeto: os "stakeholders" são todos os envolvidos no projeto e o "Sponsor" o patrocinador do projeto, ele é quem cria condições para contratação do projeto e nem sempre será usuário do mesmo ou participará do desenvolvimento dos trabalhos. Neste cenário, é importante que o gerente do projeto, conheça os interesses de todos os envolvidos e determine com clareza premissas e restrições do projeto.

Quando do detalhamento do escopo, as habilidades necessárias vão ficando mais claras. É importante se cercar de competências diversificadas e com experiência nas áreas de atuação do projeto. Alocar estes profissionais em cargos adequados também é essencial para apurar os melhores resultados. Existe a figura do profissional empreendedor, é necessário nas empresas e atualmente almejado pela grande maioria dos profissionais que chegam ao mercado de trabalho, mas existem também, os mantenedores, fundamentais para disseminação da cultura da empresa e formação de novos profissionais.

O gerente de projetos deverá ter capacidade para identificar seus aliados e aqueles que deverão ser acompanhados mais de perto, para evitar que este último grupo mine o interesse dos demais.

7. Gerenciamento da Comunicação do Projeto: $O$ gerente de projeto deve evitar a "rádio-peão". Se há um problema, o gerente de projetos pode e deve não só falar sobre ele, mas também informar que está trabalhando na solução, e não apenas comunicar que o problema existe. Problemas sem uma perspectiva de solução trazem desconforto à equipe.

Todo projeto tem uma inércia inicial. O gerente de projetos deve "provocar" as negociações preliminares. Quanto mais cedo os profissionais forem envolvidos nas negociações, mais cedo teremos soluções, minimizando os retrabalhos. Para que as propostas surjam, o gerente deverá propiciar ambiente favorável para que elas sejam apresentadas. Quem identifica o problema normalmente tem a solução, ou o caminho dela, mas precisa ser "provocado".

E para que a comunicação seja eficaz é necessário documentá-la e fazê-la chegar a quem é de interesse. É comum mais de 30 itens serem negociados em reuniões. É essencial Ata de Reunião, para que todos se lembrem de todas as deliberações e respectivas responsabilidades.

A criação de relatório gerencial ajuda muito no processo de comunicação, sobretudo por que torna o processo impessoal e mais objetivo. $\mathrm{O}$ efeito de um email onde se critica um membro da equipe pelo atraso do projeto pode ser indesejável. Ao passo que a mesma informação vinda de um cronograma com a data de término em branco, que salta aos olhos, diz tudo. 
8. Gerenciamento dos Riscos do Projeto: Após o planejamento de escopo, prazo, custo e tendo alocado os recursos corretos, é hora de desenvolver uma lista de fatores de risco e um plano para mitigá-los caso venham se tornar problemas reais. Mas além de identificar os riscos é necessário monitorar a probabilidade de ocorrência do mesmo, qual seu impacto no projeto e como enfrentá-lo.

O MS Project dispõe de um recurso que deve ser utilizado para identificar alguns riscos. Através do diagrama de Gantt, poderá ser visto o caminho crítico do projeto, ou seja, quais as atividades onde não existem margens para erros. Estas atividades deverão ser acompanhadas mais de perto e de forma pró-ativa.

Para melhor gerenciamento dos riscos, o relatório gerencial deverá abordar pontualmente os problemas e ações corretivas e ações de monitoramento que estão implementadas. Incluir também possíveis mudanças nos plano de riscos e eventualmente nos planos do projeto.

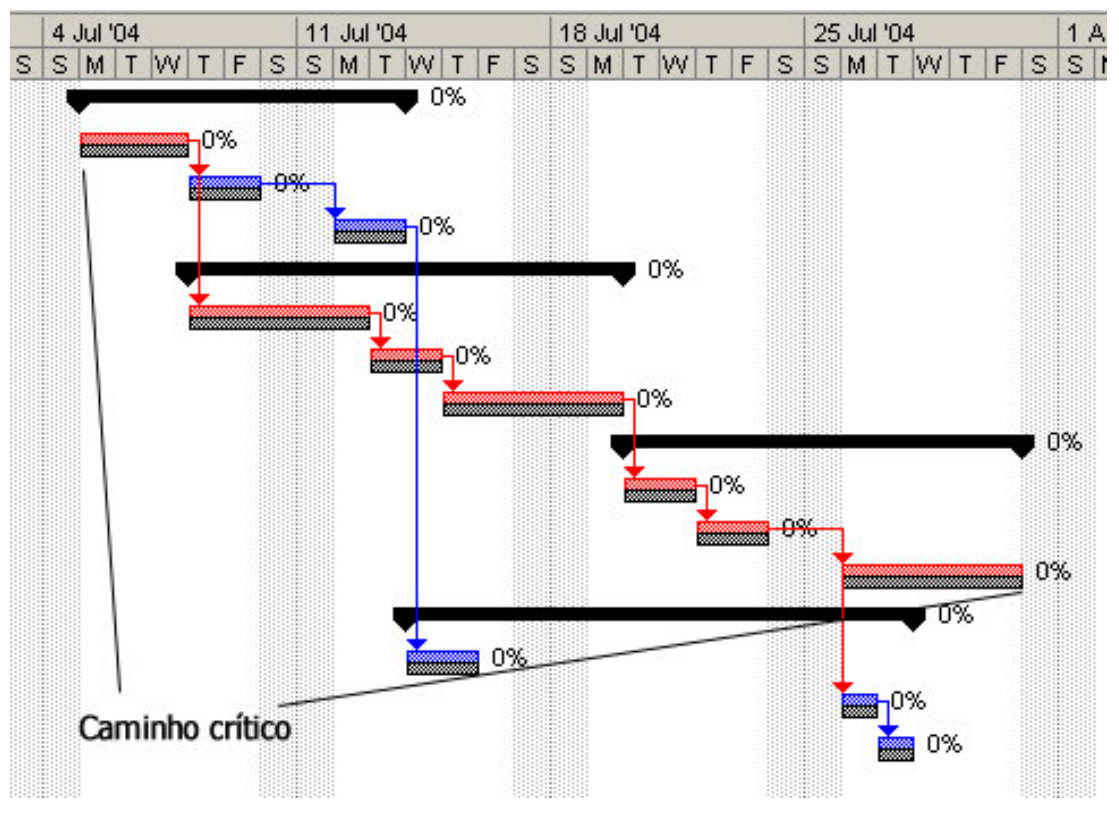

Figura 2: PERT-CHART de projeto

A imagem acima ilustra em vermelho o caminho crítico do projeto. A data de início da primeira atividade e término da última atividade resulta no tempo total do projeto. Em azul as atividades não críticas. O período entre a data de término da primeira e início da segunda é chamado folga livre. Ou seja, poderá haver atrasos iguais ao tempo da folga livre sem comprometimento da data fim do projeto.

9. Gerenciamento dos Fornecimentos de Bens e Serviços do Projeto, ou simplesmente aquisições: Tendo em vista que o bem maior de um projeto são os recursos humanos e que as aquisições que extrapolam as sub-contratações de 
fornecedores têm pequeno impacto nos custos do projeto, o gerente deverá concentrar esforços na seleção de seus recursos humanos internos e externos.

Neste caso as experiências bem sucedidas de projetos anteriores são o caminho ideal para potencializar o sucesso das contratações. Mas lembre-se, mantenha sempre um número maior de fornecedores a quem você poderá recorrer, afinal em projetos vale o velho ditado: "quem tem um, não tem nenhum".

\section{METODOLOGIA UTILIZADA}

A metodologia utilizada baseia-se, em essência, no método descrito no Guia PMBOK, porém "repaginado" (se assim podemos dizer) segundo as experiências vivenciadas em nosso escritório, e as alterações que melhor adequam a metodologia à nossa visão, em particular, e aos objetivos desejados.

Importante ressaltar que a metodologia utilizada foi pensada para projetos simultâneos e não se aplica ao modelo seqüencial.

O formato adotado é organizado, hierarquicamente, através de 07 (sete) Passos que compõe 05 (cinco) Processos e, transversalmente, ao longo de 06 (seis) Fases, assim distribuídos:

\begin{tabular}{|c|l|}
\hline \multicolumn{2}{|c|}{ PROCESSOS / PASSOS: } \\
\hline $\begin{array}{c}\text { PROCESSO 1 - } \\
\text { INÍCIO }\end{array}$ & 1'PASSO - TERMO DE REFERÊNCIA \\
\hline \multirow{2}{*}{$\begin{array}{c}\text { PROCESSO 2 - } \\
\text { PLANEJAMENTO }\end{array}$} & $\begin{array}{l}2^{\circ} \text { PASSO - CONCLUSÃO DO TERMO DE } \\
\text { REFERÊNCIA }\end{array}$ \\
\cline { 2 - 3 } & $\begin{array}{l}3^{\circ} \text { PASSO: REUNIÃO DE INÍCIO COM OS } \\
\text { "STAKEHOLDERS" }\end{array}$ \\
\hline $\begin{array}{c}\text { PROCESSO 3 - } \\
\text { EXECUÇÃO }\end{array}$ & $\begin{array}{l}4^{\circ} \text { PASSO: PROMOVER NEGOCIAÇÕES } \\
\text { TÉCNICAS }\end{array}$ \\
\hline $\begin{array}{c}\text { PROCESSO 4 - } \\
\text { CONTROLE }\end{array}$ & $\begin{array}{l}5^{\circ} \text { PASSO: GARANTIR } \\
\text { RASTREABILIDADE DAS INFORMAÇÕES }\end{array}$ \\
\hline \multirow{2}{*}{$\begin{array}{c}\text { PROCESSO 5 - } \\
\text { ENCERRAMENTO }\end{array}$} & $\begin{array}{l}6^{\circ} \text { PASSO: ENTREGA DOS TRABALHOS } \\
\text { E TERMO DE ENCERRAMENTO }\end{array}$ \\
\cline { 2 - 3 } & $\begin{array}{l}7^{\circ} \text { PASSO: REUNIÃO DE AVALIAÇÃO } \\
\text { DOS ERROS E ACERTOS DA EQUIPE }\end{array}$ \\
\hline
\end{tabular}
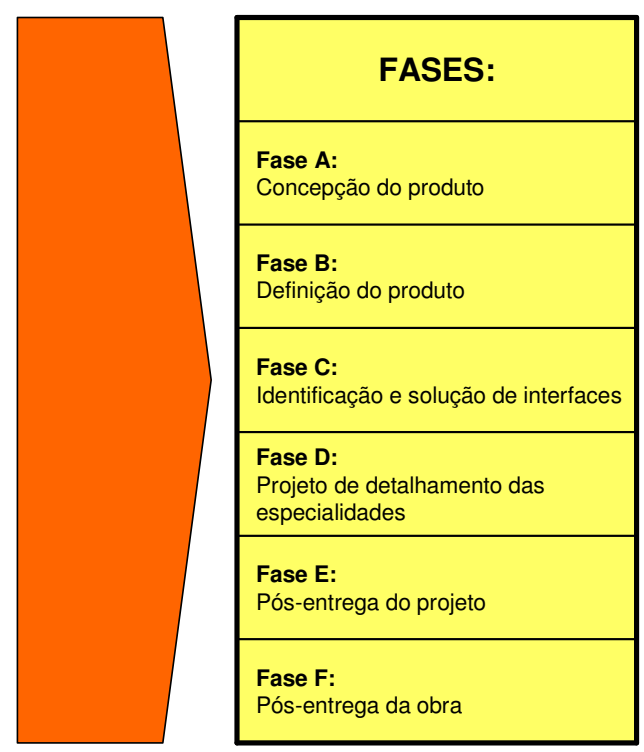

Figura 3: Passos, processos e fases de projeto 


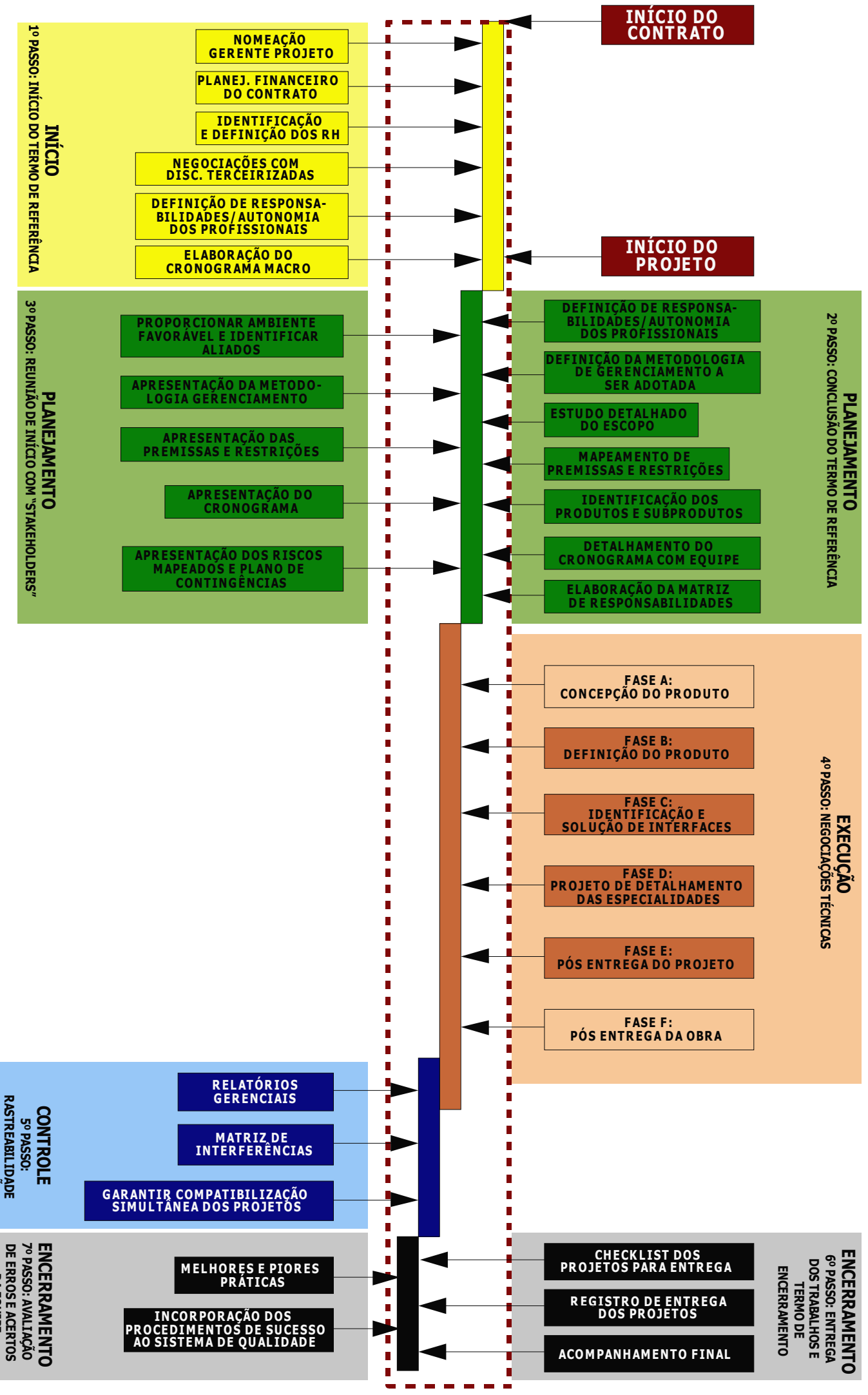

Figura 4: Mapa Chave do gerenciamento 


\section{FASE A - CONCEPÇÃO DO PRODUTO:}

\section{PROCESSO DE INÍCIO:}

\section{PASSO: INÍCIO DO TERMO DE REFERÊNCIA}

- Tudo começa com a nomeação do Gerente do Projeto. Em projetos maiores o Termo de Referência deve ser um documento assinado pelos patrocinadores e pelo gerente do projeto. Para projetos menores, pode ser uma reunião com os interessados, onde o patrocinador irá apresentar o Gerente do projeto, para que naquele momento todos saibam do inicio dos trabalhos e estejam envolvidos com a sua execução. O termo irá abranger as nove áreas do conhecimento, ou em casos de pequenos projetos irá eliminar aquelas onde gerenciá-las será mais trabalhoso e dispendioso do quê os riscos que a ingerência poderá trazer ao projeto;

- Planejamento financeiro do contrato - identificação do valor disponível para RH e terceirizações. Em algumas empresas, existe a figura do gerente de contratos, neste caso, esta responsabilidade é atribuída a ele. O gerente de projetos será informado da verba que terá para contratar e promoverá as negociações financeiras necessárias com suporte do gerente de contratos.

- Identificação e definição dos Recursos Humanos - somar competências x custos. $\mathrm{O}$ gerente deve ter autonomia para escolher sua equipe direta e o fará de acordo com as experiências bem sucedidas de projetos anteriores. Avaliará não só as competências técnicas necessárias, como também, as habilidades e atitudes fundamentais para o sucesso do projeto.

- Definição de responsabilidades x autonomia dos profissionais;

- Elaboração de cronograma macro.

\section{PROCESSO DE PLANEJAMENTO:}

\section{2॰ PASSO: CONCLUSÃO TERMO DE REFERÊNCIA.}

Nesta etapa os membros da equipe interna participarão dos trabalhos iniciados pelo gerente do projeto. As experiências vivenciadas por estes profissionais em projetos anteriores, muito ajudará no planejamento do projeto atual.

- Definição de metodologia de Gerenciamento que será adotada;

- Estudo detalhado do escopo;

- Identificação dos produtos e subprodutos;

- Mapeamento de premissas e restrições;

- Identificação dos riscos mapeamento dos planos para mitigá-los; 
- Detalhamento do cronograma, junto com a equipe que irá operacionalizar o projeto;

- Consolidação de padrões de qualidade que serão utilizados no projeto;

- Elaboração de uma Matriz de Responsabilidades.

\section{PASSO: REUNIÃO DE INÍCIO COM OS "STAKEHOLDERS".}

Após o planejamento faz-se necessário que todos os envolvidos - equipe interna, equipe externa e cliente - tenham conhecimento e estejam de acordo com as propostas ali apresentadas, caso contrário, estas insatisfações poderão comprometer os resultados dos trabalhos.

- Proporcionar ambiente favorável para que os profissionais se conheçam e que você como gerente possa identificar seus aliados;

- Apresentação da metodologia do gerenciamento;

- Apresentação e validação das premissas e restrições;

- Apresentação do cronograma;

- Apresentação dos riscos e plano de contingências;

- Apresentação dos padrões de qualidade que deverão ser respeitados;

- Apresentação da lista de interfaces, nomes, e-mail e telefones de todos os envolvidos, separados por disciplinas.

\section{PROCESSO DE EXECUÇÃO:}

\section{PASSO: PROMOVER NEGOCIAÇÕES TÉCNICAS}

Ao longo deste processo, serão desenvolvidas as 06 fases do projeto ilustradas no mapa chave abaixo. Vale ressaltar que ao longo deste processo o gerente de projeto, deverá promover reuniões técnicas sempre que necessário.

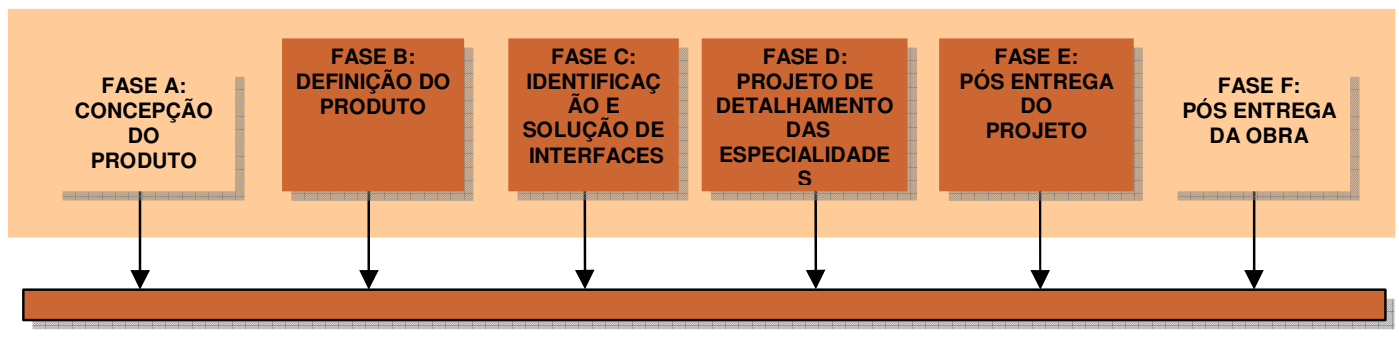

Figura 5: Negociações Técnicas

A Fase A: Concepção do produto, está representada em menor destaque, pois é comum a gerenciadora ser contratada após a conclusão deste trabalho, o que não a exime de realizar uma análise crítica dos resultados obtidos. 
Da mesma forma, a Fase F: Pós entrega da obra, nem sempre faz parte do escopo da gerenciadora. Esta realidade se torna mais comum, quando a gerenciadora faz não só o gerenciamento dos projetos, como também da obra.

\section{FASE B - DEFINIÇÃO DE PRODUTO:}

\begin{tabular}{|l|}
\hline \multicolumn{2}{|c|}{ ENTRADAS DE PROJETO: } \\
\hline $\begin{array}{l}\text { Identificação de restrições legais, na esfera } \\
\text { municipal, estadual e federal; }\end{array}$ \\
\hline Identificação de normatizações específicas; \\
\hline $\begin{array}{l}\text { Levantamento do programa de necessidades } \\
\text { ou validação de um programa apresentado } \\
\text { pelo cliente: }\end{array}$ \\
1. $\quad \begin{array}{l}\text { Entrevistas para coleta de dados. É } \\
\text { essencial mapear corretamente quem } \\
\text { serão os entrevistados; }\end{array}$ \\
2. $\quad \begin{array}{l}\text { Levantamento e conhecimento dos } \\
\text { equipamentos. No caso de }\end{array}$ \\
necessidades muito específicas, como \\
indústrias e laboratórios; \\
3. Conhecimento do fluxograma; \\
4. Identificação de acessos/ controles/ \\
restrições; \\
Identificação da população de \\
usuários/ visitantes; \\
Identificação da verba orçamentária; \\
Identificação dos sistemas e \\
subsistemas que o cliente pretende \\
utilizar. Neste caso, é bom entender as \\
razões que o levaram a determinar o \\
uso de um ou outro, para que o \\
gerente tenha melhores condições de \\
negociar, caso necessário.
\end{tabular}
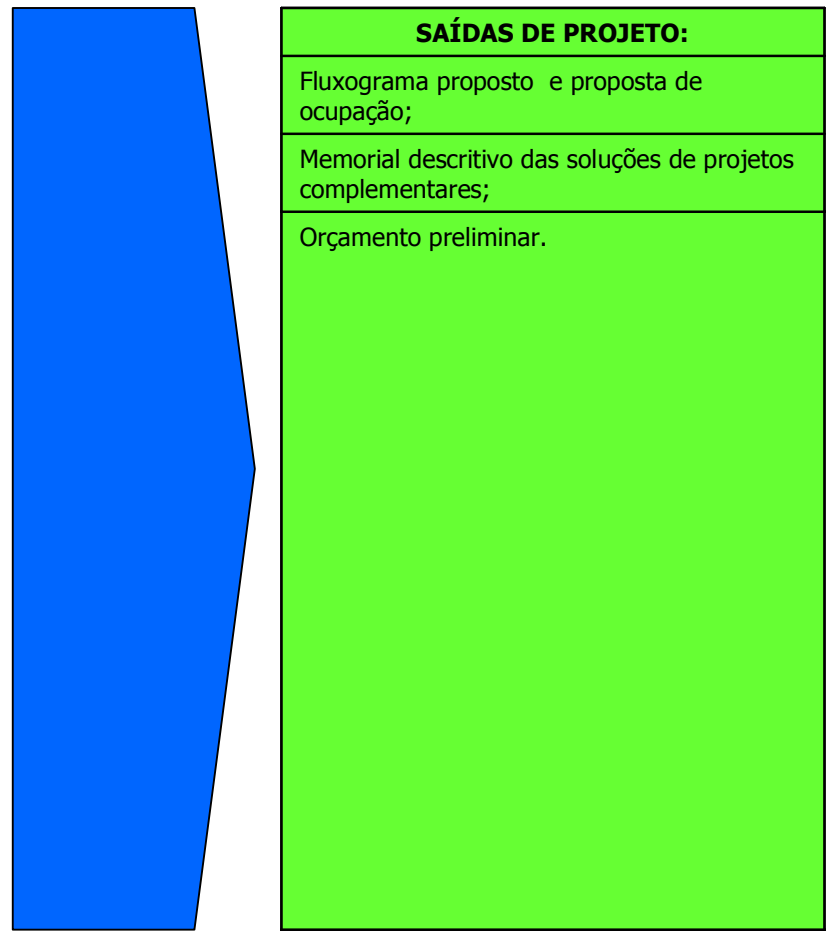

Figura 6: Definição do Produto

\section{FASE C - IDENTIFICAÇÃO E SOLUÇÃO DE INTERFACES}

\begin{tabular}{|l|}
\hline \multicolumn{1}{|c|}{ ENTRADAS DE PROJETO: } \\
\hline Reuniões de negociações;Recebimento de \\
lançamento de pilares, Croquis das salas \\
técnicas, Altura de entreforro necessária, \\
Zonas de caminhamento de tubulações \\
primárias, Lay-out dos shaft's, traçado de \\
linha dos sistemas( gases, incêndio, elétrica, \\
climatização, hidráulica, etc.). \\
\hline Reuniões de negociações; Recebimento de \\
lançamento de pilares, Croquis das salas \\
técnicas, Altura de entreforro necessária, \\
Zonas de caminhamento de tubulações \\
primárias, Lay-out dos shaft's, traçado de \\
linha dos sistemas( gases, incêndio, elétrica, \\
climatização, hidráulica, etc.).
\end{tabular}
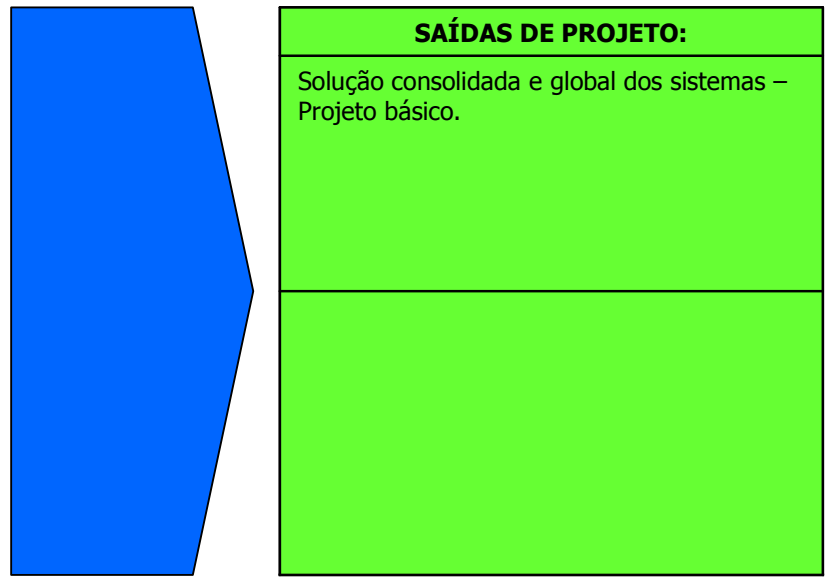

Figura 7: Definição do Produto 


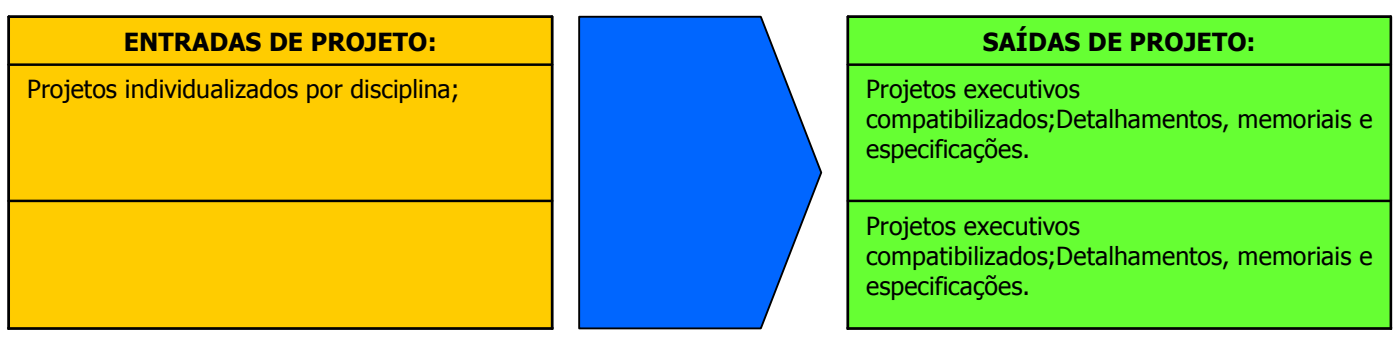

Figura 8: Detalhamento de Especialidades

FASE E - PÓS-ENTREGA DO PROJETO

\begin{tabular}{|l|}
\hline \multicolumn{1}{|c|}{ ENTRADAS DE PROJETO: } \\
\hline $\begin{array}{l}\text { Apresentação dos projetos por } \\
\text { disciplina;Esclarecimento de dúvidas. }\end{array}$ \\
\hline $\begin{array}{l}\text { Apresentação dos projetos por } \\
\text { disciplina;Esclarecimento de dúvidas. }\end{array}$ \\
\hline
\end{tabular}

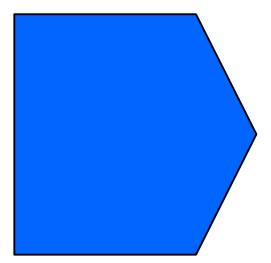

\begin{tabular}{|l|}
\hline \multicolumn{1}{|c|}{ SAÍDAS DE PROJETO: } \\
\hline $\begin{array}{l}\text { Projetos compatibilizados;Orçamento e } \\
\text { planejamento executivo de obra. }\end{array}$ \\
\hline $\begin{array}{l}\text { Projetos compatibilizados;Orçamento e } \\
\text { planejamento executivo de obra. }\end{array}$ \\
\hline
\end{tabular}

Figura 9: Pós-entrega do projeto

\section{PROCESSO DE CONTROLE:}

\section{PASSO: GARANTIR RASTREABILIDADE DAS INFORMAÇÕES}

- Relatórios Gerenciais com o progresso do projeto ajuda no processo de comunicação, sobretudo por que torna o processo impessoal e mais objetivo;

- Atualizar e acompanhar a matriz de interferências, de forma a garantir que os interessados saibam das não conformidades e soluções que devem ser dadas;

- Garantir o recebimento e a distribuição de subprodutos, para que a compatibilização seja feita simultaneamente com os projetos. Durante esta compatibilização, surgem novos itens a serem negociados.

\section{PROCESSO DE ENCERRAMENTO:}

\section{PASSO: ENTREGA DOS TRABALHOS E TERMO DE ENCERRAMENTO}

- Checklist para conferência de todos os projetos a serem entregues;

- Registro de entrega dos projetos;

- Acompanhamento até emissão do termo de encerramento do projeto. É preciso formalizar o final para que fique claro para todos os envolvidos, especialmente para o cliente, que o projeto está concluído e que novas 
necessidades serão atendidas em um novo projeto. Qualquer extensão ou alteração deverá ser orçada e todo o ciclo se inicia novamente.

\section{PASSO: REUNIÃO DE AVALIAÇÃO DOS ERROS E ACERTOS DA EQUIPE}

No Brasil, não é usual a prática de registro de erros e acertos, nem tão pouco realizar um balanço final do projeto com finalidade de avaliar a rentabilidade obtida, qualidade do produto, nível de retrabalho gerado, troca dos recursos humanos alocados, enfim, documentamos pouco, temos uma base de informações pobre para subsidiar projetos futuros.

A reunião de encerramento do projeto é o caminho mais curto para o melhoramento contínuo. Quanto mais próxima a data da reunião com a data de término efetivo, tanto melhor. A equipe ao final do projeto, quer manifestar suas satisfações e insatisfações. O gerente do projeto deverá mediar a reunião, a fim de obter informações no âmbito profissional.

- Lista das melhores e piores práticas;

- Identificação de procedimentos específicos criados que serão incorporados ao sistema da qualidade.

\section{CONCLUSÃO}

Acima de tudo, gerenciar é anteprever problemas. É planejar e acompanhar a execução com "um olho no peixe e outro gato". O gerente do projeto deve se manter alerta e flexível com os acontecimentos do dia-a-dia, mas deve estar atento ao planejamento inicial para não perder o controle. A principal qualidade do gerente de projeto é saber se comunicar bem com todos. Ele é o ponto focal das informações, nele convergem as informações que ele depois deverá processar e divulgar para todo o restante da equipe.

O segredo é envolver a equipe, cliente e fornecedores de tal forma que todos se sintam diretamente responsáveis pelo sucesso do projeto.

\section{REFERÊNCIAS BIBLIOGRAFICAS}

Associação Brasileira dos Escritórios de Arquitetura, ASBEA - Manual de Escopo de Projetos

Fabrício, M. M. Projetos Simultâneos na Construção de Edifícios. Tese (Doutorado) - Escola Politécnica. Universidade de São Paulo, São Paulo, 2002 308p.

Um Guia do Conjunto de Conhecimentos em Gerenciamento de Projetos(Guia PMBOK) Terceira edição 2004 - Project Management Institute. 